\title{
Analysis of data from South China Sea 2007: Energetics of Shoaling Solitary Waves on the Dongsha Slope Progress Report
}

\author{
Jody Klymak \\ School of Earth and Ocean Sciences \\ University of Victoria \\ P.O. Box 3055 STN CSC \\ Victoria, BC Canada, V8W 3P6 \\ phone:(250)-472-5969 fax:(250)-721-6200 email:jklymak@uvic. ca
}

Award Number: N00014-08-1-0376

http://web.uvic.ca/ jklymak/

\section{LONG-TERM GOALS}

Our long-term goal is to understand how energy is supplied to the ocean, and how it subsequently cascades to the turbulence and mixing important to the circulation, and the transport and distribution of tracers. This problem involves scales spanning sub-inertial motions to turbulence, and therefore requires integrative efforts with other sea-going investigators and numerical modelers. The South China Sea project was an ideal opportunity to investigate the cascade from internal tides to higher frequency waves though the processes of internal wave scattering and non-linear steepening.

\section{OBJECTIVES}

To understand the modification of internal tides as they encounter the continental shelf.

To understand the modification of internal solitary waves as they encounter the continental shelf. To characterize the evolution of internal solitary waves on the Dong Sha shelf.

\section{APPROACH}

Our ability to cover such a large area with limited ship resources meant that we chose to take a dual-pronged approach to understanding the wave phenomena here. We have undertaken some process-oriented 2-D numerical modeling, similar to Legg and Adcroft (2003); Legg and Klymak (2008) to provide guidance for the majority of our efforts, the sea-going observations.

Sea-going work was conducted on the Ocean Researcher I (OR1) using SIO's fastCTD system , the ship's Doppler sonar, acoustic echo sounding, and radar backscatter signatures. We operated in two modes:

- Tracking waves from depths of approximately $1000 \mathrm{~m}$ as they shoaled onto the shelf, breaking off observations when the waves had reached approximately $300 \mathrm{~m}$ water depth.

- Time series stations to make detailed observations of the internal tide. 


\section{Report Documentation Page}

Form Approved

OMB No. 0704-0188

Public reporting burden for the collection of information is estimated to average 1 hour per response, including the time for reviewing instructions, searching existing data sources, gathering and maintaining the data needed, and completing and reviewing the collection of information. Send comments regarding this burden estimate or any other aspect of this collection of information,

including suggestions for reducing this burden, to Washington Headquarters Services, Directorate for Information Operations and Reports, 1215 Jefferson Davis Highway, Suite 1204, Arlington

VA 22202-4302. Respondents should be aware that notwithstanding any other provision of law, no person shall be subject to a penalty for failing to comply with a collection of information if it

does not display a currently valid OMB control number.

1. REPORT DATE

30 SEP 2008

4. TITLE AND SUBTITLE

Analysis of data from South China Sea 2007: Energetics of Shoaling Solitary Waves on the Dongsha Slope

6. AUTHOR(S)

7. PERFORMING ORGANIZATION NAME(S) AND ADDRESS(ES)

University of Victoria,School of Earth and Ocean Sciences,P.O. Box 3055 STN CSC,Victoria, BC Canada, V8W 3P6,

9. SPONSORING/MONITORING AGENCY NAME(S) AND ADDRESS(ES)

\section{DATES COVERED}

00-00-2008 to 00-00-2008

5a. CONTRACT NUMBER

5b. GRANT NUMBER

5c. PROGRAM ELEMENT NUMBER

5d. PROJECT NUMBER

5e. TASK NUMBER

5f. WORK UNIT NUMBER

8. PERFORMING ORGANIZATION REPORT NUMBER

10. SPONSOR/MONITOR'S ACRONYM(S)

11. SPONSOR/MONITOR'S REPORT $\operatorname{NUMBER}(\mathrm{S})$

12. DISTRIBUTION/AVAILABILITY STATEMENT

Approved for public release; distribution unlimited

13. SUPPLEMENTARY NOTES

14. ABSTRACT

15. SUBJECT TERMS

16. SECURITY CLASSIFICATION OF:

a. REPORT

unclassified b. ABSTRACT

unclassified c. THIS PAGE

unclassified
17. LIMITATION OF ABSTRACT

Same as

Report (SAR)
18. NUMBER 19a. NAME OF

OF PAGES RESPONSIBLE PERSON

6 


\section{WORK COMPLETED}

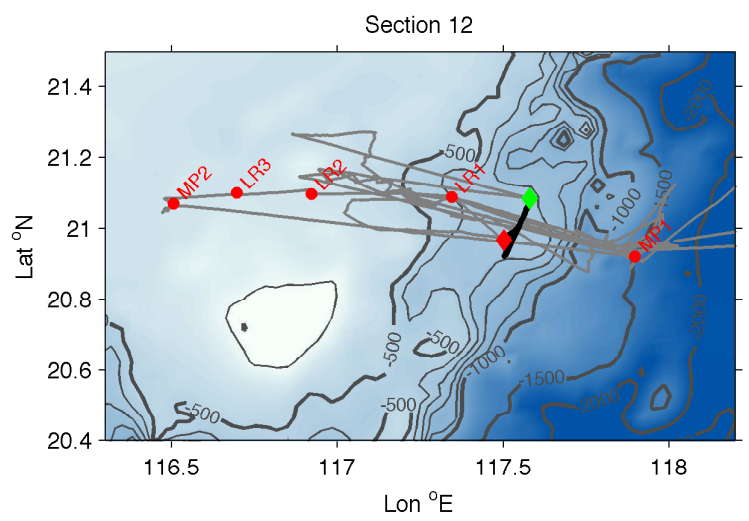

Figure 1: Cruise track from 25 Apr-9 May of the OR1. Location of a one-day time series on the 700-m isobath is shown in heavy lines. Moorings deployed by Lien and Alford are noted with red diamonds.

Pre- and post-cruise numerical modeling were carried out at UVic, yielding the results described below.

The group participated in a cruise on the OR1 from 25 Apr-9 May, 2007. The chief scientist was Y.J. Yang from CNA, and Ren-Chieh Lien and Matthew Alford (APL/UW) were aboard. We tracked waves from Alford's MP1 mooring at $1500 \mathrm{~m}$ depth to Lien's LR2 mooring in $300 \mathrm{~m}$. We also occupied time series stations at the 700 and $1200-\mathrm{m}$ isobaths.

\section{RESULTS}

We tracked four sets of solitary waves up the shelf using Doppler sonar, acoustic backscatter, and the fastCTD. An example packet is shown in figure 2. Here a wave has been tracked from 450-m to 300-m depth. It appears that the core of the wave is made up of very isothermal water, indicating a trapped core. However, the water in the wave warms as it moves upshelf, indicating communication with the surrounding water, either via mixing or advection. Hints of transformation of the wave can be seen in the last panel where the depth shoals abruptly.

We have three other sections that we will analyze in a similar manner and compare with the mooring observations. The advantage of the fastCTD measurements is that we fully measure the density field, so this will be an invaluable for calibrating the acoustic mooring data for energy fluxes.

The pre-cruise numerical modeling indicated that the transformation of waves may happen at the shelf-break (figure 3). This model was initialized with an offshore solitary wave propagating onshelf. When it hit the critical region (near $100 \mathrm{~km}$ in the figure), there was some scattering. The wave also spawned a second wave. We will be able to test this result with the data collected during the experiment. This fissioning process is important to predicting the character of the waves on the shelf.

We also investigated the incoming internal tide and its modification as it shoals on the continental slope. Shipboard measurements of the bottom bathymetry indicated that the continental slope was close to critical to the diurnal tide (i.e. the slope was equal to the internal wave ray angles) just off-slope of the 
700-m isobath, so we occupied a station at this location (figure 1) for 27 hours (5 May). The resulting observations show a very non-linear internal tidal response (figure 4) with onshore flow having a steeper rise than the offshore relaxation, so that the onslope flow resembles a bore. Like a bore, the internal tide in the lower $400 \mathrm{~m}$ is very turbulent as diagnosed from density overturns. The turbulence remains elevated for over 6 hours, indicating the region is a strong sink for the internal tide.

The response at this location is very reminiscent of observations the group made at the Hawaiian Ridge, where onslope flow was found to be very turbulent (Klymak et al., 2008b), so we suspected a similar mechanism as was found there. In order to aid our data interpretation we again used the MITgcm to run an idealized experiment (figure 5). For this model a mode-1 internal diurnal tide was sent towards the continental shelf and the response monitored. The most obvious feature is that the mode-1 tide scatters to form abrupt tidal rays, predominantly propagating onslope. In the onslope phase of these rays (the blue bands) the isopycnals are very vertical, and correspond to the observed bore-like features. This response actually seems unique from the Hawaii response, because at Hawaii the non-linearities were not carried in tidal beams, but in trapped hydraulic waves. Similar features are evident in this model, but do not appear to carry most of the bore-like flow.

Additional work is just starting on this data set. In the meantime, Klymak et al. (2009) have been numerically exploring the flow regimes important to these processes. Surprisingly, a basic case - steady stratified flow over large topography $N h / U>>1$, has not been explored yet. Our findings are that significant simplifications to the flow are observed that allow us to make predictions of the form drag, time response, and wavelength of these inherently non-linear features. Our next step in this process is to extend these ideas to a model of energy lost from internal tides due to the direct breaking process, observed at Hawaii and at this location (Klymak et al., 2008a).

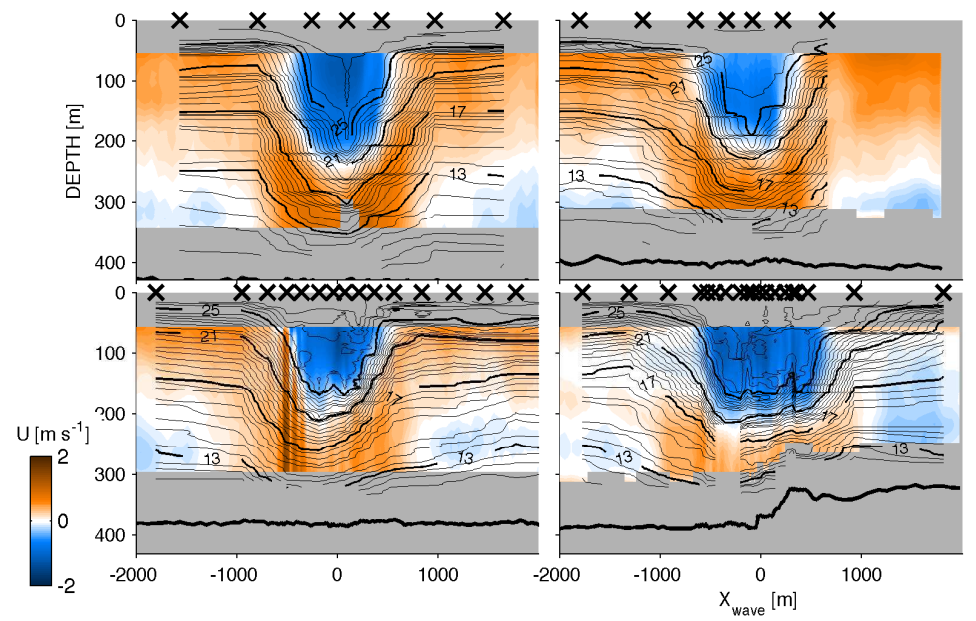

Figure 2: Results from wave tracking (5 May). Wave has been put into an approximate frame of reference moving with the wave. Surface water can be clearly seen pulled down into the core of the wave. The last panel hints at major along-path transformations. 


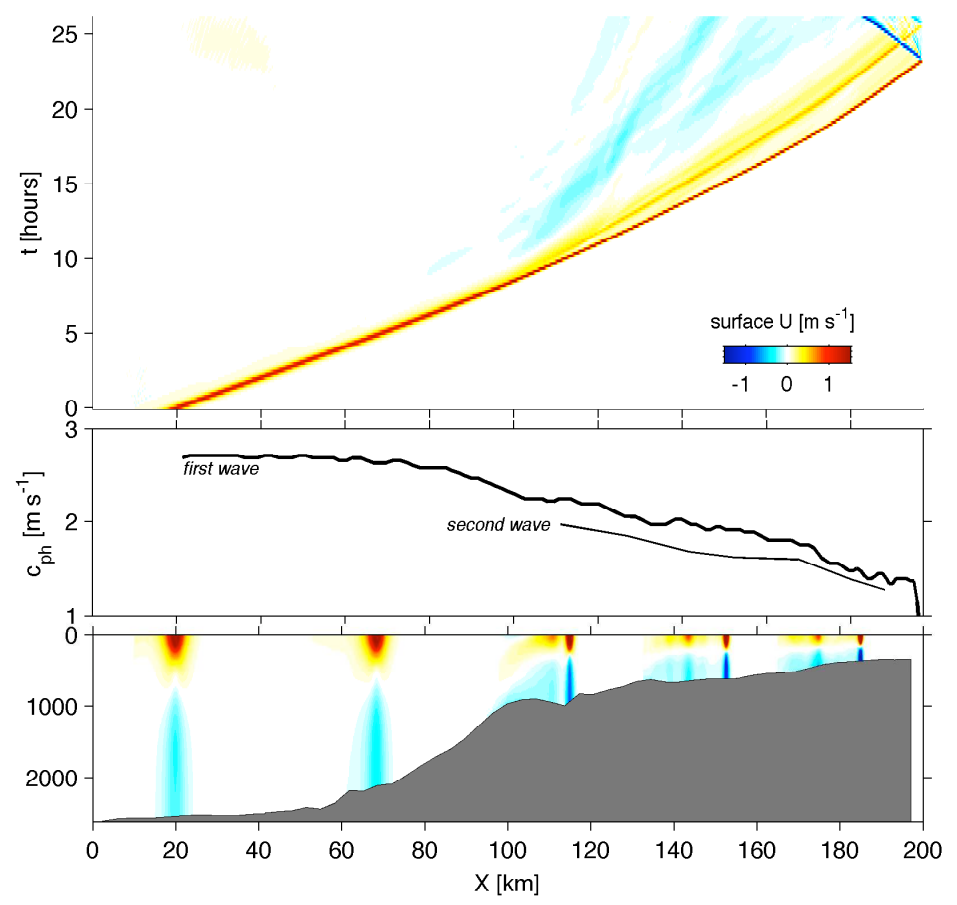

Figure 3: Model Hovmoller diagram showing near-surface velocity as a function of space and time. Second panel is the estimated wave speed of the lead wave and the second wave when it separates from the lead wave. Lower panel is five snapshots of the wave velocity structure. The wave remains essentially mode-1 throughout its transit up the shelf. It loses energy to scattering and to making smaller trailing waves.

\section{IMPACT/APPLICATIONS}

Understanding the transformation of the relatively easy to observe trans-basin waves to the zoo of shelf waves is a major challenge to predicting sound properties on the continental shelf. We hope these observations, coupled with Lien and Alford's mooring array, can help make progress on this.

We think we have identified an important mechanism for scattering and dissipating low-mode internal tides. This set of observations and the accompanying modeling should help in our ultimate goal of modelling these processes in the ocean.

\section{RELATED PROJECTS}

This work is strongly tied to the work by PIs Lien and Alford. We will be collaborating extensively with them in data analysis.

It is related to the work being done in the AESOP DRI, which also seeks to understand the mechanisms that break low-mode energy down into high-mode unstable waves.

Finally, it is complimentary to Klymak's work at UVic, funded through the Canadian National Science and Engineering Research Council, to look at coastal internal wave processes. 


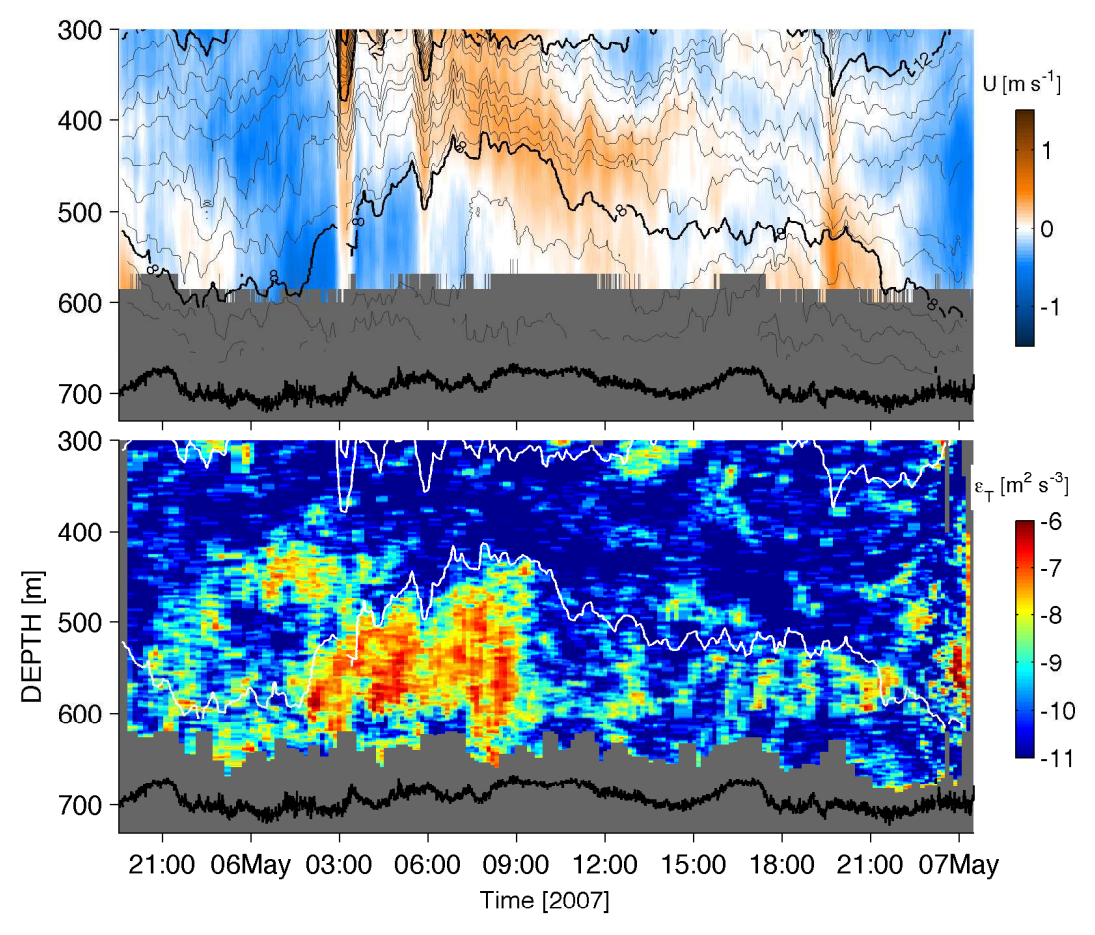

Figure 4: Internal tide response just onshelf of the critical point on the continental slope. Upper plot is east-west velocity, with blue being onslope. Lower plot is the logarithm of the turbulence dissipation rate $\varepsilon$.

\section{REFERENCES}

Klymak, J. M., S. Legg, and R. Pinkel, 2009: High-mode hydraulics in stratified flow over large obstacles, submited to J. Fluid Mech.

Klymak, J. M., R. Pinkel, and S. Legg, 2008a: A simple parameterization of tidal turbulence near super-critical topography. Ocean Sciences, AGU/ASLO.

Klymak, J. M., R. Pinkel, and L. Rainville, 2008b: Direct breaking of the internal tide near topography: Kaena Ridge, Hawaii. J. Phys. Oceanogr., 38, 380-399.

Legg, S., and A. Adcroft, 2003: Internal wave breaking at concave and convex continental sloped. $J$. Phys. Oceanogr., 33, 2224-2246.

Legg, S., and J. M. Klymak, 2008: Internal hydrualic jumps and overturning generated by tidal flow over a steep ridge. J. Phys. Oceanogr., 1949-1964. 


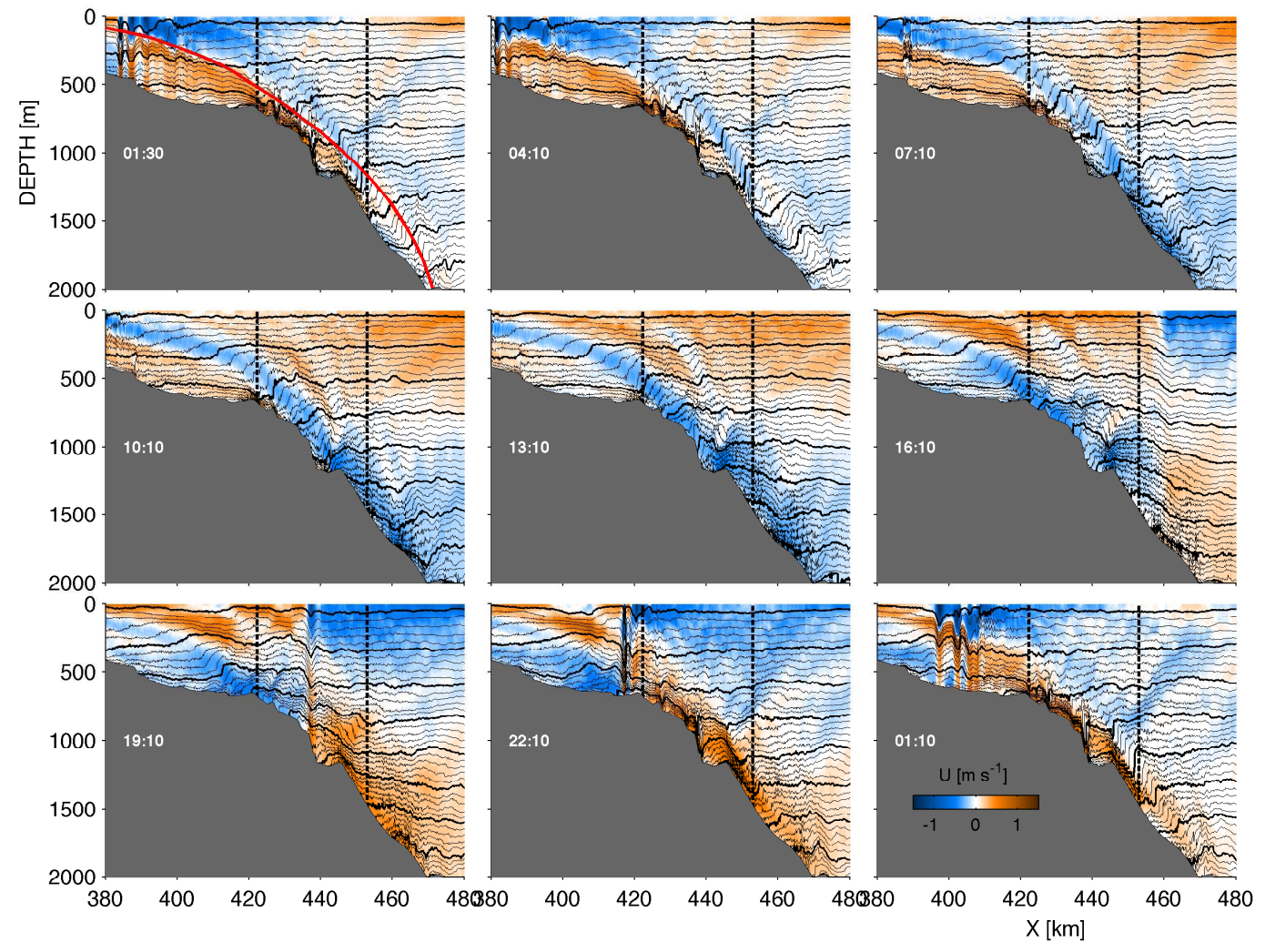

Figure 5: Velocity and density contours from idealized numerical simulation of an internal tide propagating onto the continental shelf. The location of Alford's mooring and our 700-m deep time series are indicated with dashed vertical lines. 